\title{
Collectivism And Religious Affiliation As Predictors Of The Multidimensional Measure Of Leader-Member Exchange (LMX-MDM)
}

Phyllis Duncan, Ph.D., Our Lady of the Lake University, USA

Richard Herrera, Ph.D., Texas A\&M University-Texarkana, USA

\begin{abstract}
Drawing upon the existing literature, this study investigated the relationship between collectivism and religious affiliation with the four Leader-Member Exchange (LMX) dimensions of Contribution, Loyalty, Affect, and Professional Respect. In this study of 300 adults, a significant positive relationship was found between the Multidimensional Measure of Leader-Member Exchange with collectivism and religious affiliation. With regard to the dimension of Contribution, collectivism and religious affiliation were both found to be strong predictors. With respect to Loyalty; collectivism and age helped to increase ratings of the supervisor and perceptions of leadership. Affect only had one significant predictor, collectivism. The LMX dimension of Professional Respect was found to have four significant predictors, including collectivism, religious affiliation, age, and years as a manager. Further regression analysis indicated that the diversity dimension, collectivism, was the driving factor of the relationship. This outcome indicated that collectivism was a strong predictor of how positively participants rated their attitudes toward their immediate supervisor and perceptions of leadership. The results of this study indicate that a relationship does exist between collectivism and religious affiliation with the Multidimensional Measure of Leader-Member Exchange, particularly with regard to the LMX dimensions of Contribution and Professional Respect. Furthermore, it strengthens the argument that organizations must be prepared to re-evaluate their policies with regard to diversity in the organization, particularly with respect to collectivism.
\end{abstract}

Keywords: Diversity; Leader-Member Exchange (LMX); Collectivism; Multidimensional Measure Of LeaderMember Exchange (LMX-MDM)

\section{INTRODUCTION}

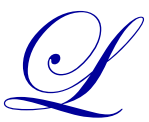

iterature in organizational behavior and industrial and organizational psychology have generally been mixed on the relationship between diversity and the leader-member exchange model, particularly with respect to collectivism and religious affiliation. Previous studies (Williams \& Bauer, 1994; Gilbert \& Stead, 1999; Avery, 2003) overlooked the quality of applicants who are attracted to diversity management. Other studies, such as Cox and Blake (1991), Agocs and Burr (1996), and Robinson and Dechant (1997) proposed that diversity management reduces turnover and absenteeism, attracts the best workers, increases sales and marketing efforts, enhances creativity and innovation, and improves decision making. More recent studies (Herrera, Duncan, Green, Ree, \& Skaggs, 2011; Shen, D’Netto, \& Tang, 2010; Bell, Villado, Lukasik, Belau, \& Briggs, 2011) further indicate that organizational diversity helps foster positive individual and team performance relationships.

Recent studies in the workforce have shown that by the year 2020 there will not be enough replacement workers to fill the void by those retiring (Somers, Finch, \& Birnbaum 2010). To make up for this loss, leaders will need to come up with ways to transfer knowledge from older workers to new workers, retain their existing 
workforce, and to fill vacancies from a decreasing number of available candidates (Meyers \& Dreachslin, 2007). According to Meister and Willyerd (2010), there will be a dramatic change in the composition of the American workforce. In The 2020 Workplace, they write that the workplace of the future "will be one that provides workers a personalized, social experience which attracts, develops, and engages employees across all generations and geographies" (p. 72). This will require leaders whose management styles create and enforce this type of environment. One of the key instruments that can measure this relationship between the leader and the employee is the Multidimensional Measure of Leader-Member Exchange (LMX-MDM).

The 2020 workforce crisis was first acknowledged more than 20 years ago by Paul Volcker, former Federal Reserve Board Chairman (Charles, 2003). He further added that this deficit was occurring at the same time when the demographics of the population were changing. Johnston and Packer (1987), in their Hudson Institute's Workforce 2000 report, also forecasted a decrease in workforce growth as well as an accelerated growth of women and ethnic minorities in the years to follow. Based on these findings, some organizations made the decision to become more inclusive, integrating women and people of color. The Hudson Institute subsequently followed up with another report, Workforce 2020, which predicted even more gradual changes in the workforce (Judy \& D'Amico, 1997). The study forecasted a steady increase in the number of women in the workforce, as well as a growth in minorities. The report further asserted that women of all races would constitute half of the entire workforce by 2020 .

The distribution of the workforce is even more demographically diverse than ever before. This makes incorporating diversity initiatives into human resource planning even more crucial. Managing diversity in the workplace will be just as crucial as organizations make provisions for this increase in women, minorities, and older workers in the next decade. One way for organizations to confront this challenge will be not only to continue any diversity efforts already in place, but to become more diverse within its ranks.

This study attempts to examine the relationship between the Multidimensional Measure of Leader-Member Exchange (LMX-MDM) with collectivism and religious affiliation. We selected the GLOBE study (House, Hanges, Javidan, Dorfman, \& Gupta, 2004, p. xv) component of collectivism as a measure of diversity for the present study, as well as religious affiliation because we believe that (a) the components of collectivism and religious affiliation in an organizational context has a significant influence on employee's perceptions of their supervisor's leadership style and (b) no studies to our knowledge have investigated the relationship between these two constructs and LMX dimensions. Taking the lead from recent literature, we hypothesize that the GLOBE dimension, collectivism, and religious affiliation are associated with multidimensional measures of LeaderMember Exchange (LMX). In other words, leaders who possess the dimensions of collectivism and religious affiliation are likely to exhibit increased behaviors associated with multidimensional leadership.

Consequently, making a business case for diversity alone is no longer adequate. Organizations must not only focus on the strategic dimension of diversity policies and processes, but also on the dimensions of leadership that impact the leader-member exchange relationship and organizational outcomes. Not until this is acknowledged can the full benefits of organizational diversity be achieved.

\section{Diversity}

Initial research on diversity was mainly focused on the problems associated with diversity, such as discrimination, bias, affirmative action, and tokenism (Shore, Chung, Dean, Ehrhart, Jung, Randel, \& Singh, 2009). As the diversity field has evolved, researchers have focused on ways in which diversity can harness the most from diverse employees, eliminate conflict in the workplace, and enhance organizational performance outcomes (Herrera, Duncan, Green, \& Skaggs, 2012; Gonzalez \& DeNisi, 2009; Homan, Hollenbeck, Humphrey, van Knippenberg, Ilgen, \& Van Kleef, 2008). Since diversity is essentially about cultural norms and values, the focus is on creating a truly inclusive work environment where individuals from diverse backgrounds feel valued and respected. This culture of inclusion is an organizational environment that recruits people of different backgrounds and ways of thinking who work together and perform to their highest potential to achieve organizational objectives. Not until this is acknowledged, and diversity is culturally valued, can the full benefits of diversity be achieved which may include attracting and retaining the best candidates, higher creativity and innovation, better problem solving, and more organizational flexibility (Cox \& Blake, 1991). For the purposes of this study the components of diversity and collectivism are defined as follows: 
1. Diversity, or workforce diversity, is defined as "the uniqueness of all individuals, which encompasses differences and similarities in personal attributes, values, work and life experiences, and organizational roles" (Carr-Ruffino, 1992).

2. Collectivism is defined as the degree to which organizational and societal institutional practices encourage and reward collective distribution of resources and collective action (House et al., 2004).

\section{Collectivism}

Of the cross-cultural studies that have been performed, the emphasis on individualism vs. collectivism has been the most important dimension of cultural differences (Triandis 1990). It was Hofstede's 1980 study on national and organizational cultures that first focused on the cultural dimensions of individualism and collectivism, which he defined as follows:

Individualism pertains to societies in which the ties between individuals are loose; everyone is expected to look after himself or herself and his or her immediate family. Collectivism as its opposite pertains to societies in which people from birth onwards are integrated into strong, cohesive in-groups, which throughout people's lifetime continue to protect them in exchange for unquestioning loyalty. (p. 51)

People from cultures that are individualistic focus mostly on individual goals, and their successes or achievements, and aim to climb up the hierarchical ladder. People from collectivistic cultures, on the other hand, become so highly interdependent with the organization that the organization becomes a part of the employee's selfidentity.

Although some studies suggest that interactions between individualism and collectivism might result in confusion and prevent effectiveness in the workplace (Barak 1999; Harrison, Price and Bell 1998), other researchers believe that cultural diversity in the workplace, if properly managed, can serve as a competitive advantage and allow new creative and different ways of problem solving ( $\mathrm{Ng}$ and Tung 1998).

Given this reasoning between individualism and collectivism, we can interpret the results of the current study as follows: Study results indicated that the diversity dimension, collectivism, was the driving factor of this relationship. This result further indicates that the more collectivistic the respondents believed their organizations' work culture to be the more positively they rated their immediate supervisor and perceptions of leadership.

\section{Religious Affiliation}

Although religion continues to play a large role in today's environment, many researchers have not explored the relationship between religion and organizations as one would expect. According to Tracey (2012), the reasons for this may be because the issues surrounding religion are too far removed from the actual workplace or it may simply be deemed too sensitive an issue to address. Although management has ignored the effects of religion for many years, organizations are coming to the realization that nurturing spirituality in the workplace can be very beneficial. Both workers and managers are realizing that religion or spirituality is a means by which many in the workforce can achieve an inner strength. Friedlander (1975), Furnham (1977), Nielsen and Edwards (1982), and Sagie \& Elizer (1996) are just a few of the studies in which religion is examined. Proffitt and Spicer (2006) further reinforces the idea that religious organizations may play influential and unnoticed in social movements and social change. Understandably, a study by Giacalone and Jurkiewicz (2003) notes that the interest in spirituality in the workplace is increasing at an accelerated rate. In the current study religious affiliation was found to be a strong predictor with regard to the LMX dimensions of Contribution and Professional Respect. With regard to Contribution, having a religious affiliation and the more collectivistic the organizational culture, the more positively the respondents rated their relationship quality with the leader-member exchange. With Professional Respect, the more collective the organizational culture, the more years as a manager, the younger the individuals, and having a religious affiliation, the more positively participants rated their leader-member exchange. 


\section{Multidimensional Measure of Leader-Member Exchange (LMX-MDM)}

Over the past few decades the LMX model has emerged as one of the most enduring theories for characterizing leadership behavior and understanding its consequences (Liden, Sparrowe, \& Wayne, 1997; Nahrgang, Morgeson, \& IIies, 2009; Schriesheim, Castro, \& Cogliser, 1999). The theoretical basis for the LMX theory is the concept of the "negotiated" role that both the leader and subordinate assume in their respective positions. This model stipulates that leaders have a vested interest in the performance of their subordinates and will demand certain expectations. This "interpersonal exchange relationship" in part determines the type of role that the subordinate will assume within the organization (Graen, 1976, p. 1206). Due to time constraints, the leader is only able to develop a close relationship with a select few. As a result, two types of leader-member exchanges transpire: the in-group category (characterized by high trust, interaction, support, and rewards) and the out-group (characterized by low trust, interaction, support, and rewards).

Previous research has shown that the Leader-Member Exchange Theory follows one of two types, one that is unidimensional and the other being multidimensional. Early research showed the LMX to be unidimensional and based upon the work behaviors of leaders and subordinates, thus representing the role theory (Graen, 1976; Graen \& Scandura, 1987; Graen \& Uhl-Bien, 1995). The multidimensional theory stresses that roles are multidimensional and include those that focus on their tasks while neglecting social interactions, some that focus on social interaction and not tasks, and others that may be weak or strong on both dimensions (Graen, 1976; Katz \& Kahn, 1978; Jacobs, 1971).

Following Dienesch and Liden (1986), Liden and Maslyn (1998) proposed that the LMX model is associated with the multidimensional dimensions of Contribution (the perception of the amount, direction, and quality of work-oriented activity each member puts forth toward the mutual goals, explicit or implicit, of the dyad), Loyalty (the extent to which both leader and member publicly support each other's actions and character), and Affect (the mutual affection members of the dyad have for each other based primarily on interpersonal attraction rather than work or professional values). In addition to the three dimensions identified by Dienesch and Liden, the study by Liden and Maslyn on the LMX as a multidimensionality construct, provided support for a fourth dimension, Professional Respect (the perception of the degree to which each member of the dyad has built a reputation, within and/or outside the organization, of excelling at his or her line of work). Leaders who possess and implement the characteristics of diversity may be associated with the leader-member leadership exchange model for several reasons. The diversity dimension of individualism is likely to be associated with Loyalty, as this involves a faithfulness to the individual that is generally consistent from situation to situation. Collectivism, which is associated with the extent to which the supervisor provides resources and opportunities for completed tasks that extend beyond the job description and/or employment contract, is likely to be associated with Contribution. Gender egalitarianism involves providing a level of regard or respect to each member of the dyad without regard to gender. Employees are likely to respect and identify with a leader who is considerate and is willing to help employees to be effective and improve their job performance. Therefore, the Gender Egalitarianism dimension of Diversity is likely to be associated with Professional Respect.

Developed by Liden and Maslyn (1998), the LMX model is a widely used instrument to assess the four aspects of Leader-Member Exchange which include the dimensions of Affect, Loyalty, Contribution, and Professional Respect.

\section{RESEARCH PROPOSITIONS}

In this paper, we will attempt to address the significance of collectivism and religious affiliation as predictors of the Leader-Member Exchange Model. We begin by presenting a discussion on the importance of diversity, followed by a review of the GLOBE study component of collectivism and religious affiliation. A review of the recent literature on the Leader-Member Exchange Theory that addresses leadership behavior is then presented. Results of this study indicated that the diversity dimension, collectivism, was the driving factor of leadership effectiveness, through the use of the LMX model. Following are the proposed hypotheses for this study: 
Hypotheses 1: The diversity dimension of collectivism is positively associated with the multidimensional measure of leader-member exchange.

Hypotheses 2: The dimension of religious affiliation is positively associated with the multidimensional measure of leader-member exchange.

\section{METHODS}

\section{Instruments}

The participants in this study were provided with three instruments to complete. The first instrument was the LMX-MDM model, which consisted of the four dimensions of Contribution, Loyalty, Affect, and Professional Respect. The purpose of this 12-item questionnaire was to measure the subordinate's attitudes toward their immediate supervisor and perceptions of leadership. Respondents were asked twelve questions on a Likert scale of 1 representing strongly agree, 4 representing neither disagree nor agree, and 7 representing strongly disagree. These scores were reversed-scored to coincide with the original empirical scale which asked the twelve questions on a Likert scale of 1 representing strongly disagree, 4 representing neither disagree nor agree, and 7 representing strongly agree, identified by Liden and Maslyn (1998). The participants were then asked to complete a diversity questionnaire. The diversity dimension of collectivism was measured with four questions from the GLOBE research survey. Since we were mainly interested in how diversity and organizational practices were perceived by participants participating in this research, only the questions dealing with the diversity dimension of collectivism were asked in this survey. The four questions $4,5,6$, and 8 on collectivism were reversed-scored according to the Syntax for GLOBE National Culture, Organizational Culture, and Leadership Scales. Finally, participants were asked to complete the demographic questions from the GLOBE Survey, which consisted of 27 questions.

\section{Participants}

A total of 300 adults participated in this study. Of those, 185 (61.7\%) were women and 115 (38.3\%) were men. Thirty-nine percent of the respondents self-reported as Hispanic, while participants who self-reported as White, Caucasian, or Anglo constituted 38\% of the sample. Participants who self-reported as Black, or African American constituted $16 \%$ of the sample. The remaining 7\% identified themselves as American Indian, Asian Indian, Korean, or Other Pacific Islander. Participants ranged in age from 18 to $78 ; 37.3 \%$ were 18 to 30 years old, $24.0 \%$ were 31 to $40,22.7 \%$ were 41 to $50,13.7$ were 51 to 60 , and $2.3 \%$ were 61 to 78 years of age. Ninety-eight respondents $(32.9 \%)$ had earned less than an undergraduate degree, 107 respondents $(35.9 \%)$ held a bachelor's degree, and 95 respondents $(31.2 \%)$ had earned postgraduate degrees. On religious affiliation, $87.6 \%$ of the respondents indicated a religious affiliation while $12.4 \%$ indicated no religious affiliation.

\section{RESULTS}

In this analysis, the four LMX dimensions of Contribution, Loyalty, Affect, and Professional Respect were used as the dependent variables. The diversity dimension of collectivism was used as the independent variable. The control variables consisted of age, gender, religious affiliation, years of work experience, years of education, ethnicity, years as a manager, tenure in current job, and number of direct reports.

Likert scales were used in the diversity questionnaire to measure participant's attitudes toward diversity in their organization. The reliability of the Likert scales resulted in a Cronbach $\alpha$ of .60, which indicated that the questions measuring attitudes toward diversity, were moderate to highly correlated with each other. The mean scores for each of the questions ranged from 3.82 to 4.39 , on a scale of 1 being a strong measure of diversity attitudes in the organization, 7 being a weak measure of diversity attitudes in the organization, and 4 being undecided. Ultimately, all questions on collectivism that measured diversity were summed into one variable. An overall mean score of 4.48 on a scale of 1-7 indicated that attitudes toward diversity for all surveys combined ranged between average and strong. 
A Pearson's correlation of the LMX model was run using the LMX dimensions of Contribution, Loyalty, Affect, and Professional Respect and the diversity dimension of collectivism. The results of this correlation in Table 1 indicated that the independent variable labeled collectivism was significant and found to be positively correlated with the dependent variable labeled LMXQuality $(r=.54, \mathrm{p}<.01)$, Contribution $(r=.24, \mathrm{p}<.01)$, Loyalty $(r=.35$, $p<.01)$, Affect $(r=.40, p<.01)$, and Professional Respect $(r=.41, p<.01)$.

Table 1. Pearson's Correlations on LMX Dimensions and Diversity

\begin{tabular}{|c|c|c|c|c|c|}
\hline & LMXQuality & $\begin{array}{c}\text { Collectivism } \\
\text { Mean }\end{array}$ & Age & $\begin{array}{c}\text { Religious } \\
\text { Affiliation } \\
\end{array}$ & $\begin{array}{l}\text { \# Direct } \\
\text { Reports }\end{array}$ \\
\hline \multicolumn{6}{|l|}{ LMX Quality } \\
\hline Pearson Correlation & 1 & $.543 * *$ & 0.91 & $.132 *$ & -.056 \\
\hline Sig. (2-tailed) & & .000 & .116 & .023 & .358 \\
\hline $\mathrm{N}$ & 298 & 298 & 298 & 296 & 272 \\
\hline \multicolumn{6}{|l|}{ Age } \\
\hline Pearson Correlation & -.091 & $-.214 * *$ & 1 & .110 & $.265 * *$ \\
\hline Sig. (2-tailed) & .116 & .000 & & .058 & .000 \\
\hline $\mathrm{N}$ & 298 & 299 & 300 & 298 & 274 \\
\hline \multicolumn{6}{|l|}{ Religious Affiliation } \\
\hline Pearson Correlation & $.132 *$ & $.127 *$ & .110 & 1 & -.056 \\
\hline Sig. (2-tailed) & .023 & .029 & .058 & & 356 \\
\hline $\mathrm{N}$ & 296 & 297 & 298 & 298 & 273 \\
\hline \multicolumn{6}{|l|}{ \# Direct Reports } \\
\hline Pearson Correlation & -.056 & $-.144 *$ & $265 * *$ & -.056 & 1 \\
\hline Sig. (2-tailed) & .358 & .017 & .000 & 356 & \\
\hline $\mathrm{N}$ & 272 & 273 & 274 & 273 & 274 \\
\hline \multicolumn{6}{|l|}{ Collectivism Mean } \\
\hline Pearson Correlation & $.543 * *$ & 1 & $-.214 * *$ & $.127 *$ & $-.144 *$ \\
\hline Sig. (2-tailed) & .000 & & .000 & .029 & .017 \\
\hline $\mathrm{N}$ & 298 & 299 & 299 & 297 & 273 \\
\hline
\end{tabular}

*Correlation is significant at the 0.05 level (2-tailed).

***orrelation is significant at the 0.01 level (2-tailed).

Multiple regression analysis was conducted on the dependent variable LMXQuality, using the stepwise method to determine which, if any, of the diversity dimensions had any relationship with the LMX model. Results of the regression analysis provided in Table 2 indicated that the diversity dimension, collectivism, was the driving factor of the relationship $(\beta=.539, p=.00$ ). Thus, results showed that the more collectivistic the respondents believed their organizations' work culture to be the more positively they rated their immediate supervisor and perceptions of leadership. 
Table 2. Regression coefficients for the LMX Dependent Variable: LMXQuality

\begin{tabular}{|c|c|c|c|c|c|c|}
\hline & \multirow{2}{*}{ Model } & \multicolumn{2}{|c|}{ Unstandardized Coefficients } & \multirow{2}{*}{$\begin{array}{c}\begin{array}{c}\text { Standardized } \\
\text { Coefficients }\end{array} \\
\text { Beta } \\
\end{array}$} & \multirow[t]{2}{*}{$\mathbf{t}$} & \multirow[t]{2}{*}{ Sig. } \\
\hline & & B & Std. Error & & & \\
\hline \multirow[t]{2}{*}{1} & (Constant) & 74.530 & 3.229 & & 23.080 & .000 \\
\hline & Religious Affiliation & 6.132 & 2.778 & .137 & 2.207 & .028 \\
\hline \multirow[t]{3}{*}{2} & (Constant) & 74.409 & 3.282 & & 22.671 & .000 \\
\hline & Religious Affiliation & 6.214 & 2.809 & .139 & 2.213 & .028 \\
\hline & Ethnicity & .105 & .480 & .014 & .218 & .827 \\
\hline \multirow[t]{6}{*}{3} & (Constant) & 75.393 & 3.443 & & 21.900 & .000 \\
\hline & Religious Affiliation & 6.441 & 2.816 & .144 & 2.287 & .023 \\
\hline & Ethnicity & .122 & .491 & .016 & .249 & .804 \\
\hline & Yrs as Manager & .143 & .117 & .088 & 1.215 & .225 \\
\hline & Tenure Current Job & -.241 & .155 & -.110 & -1.555 & .121 \\
\hline & \# Direct Reports & -.026 & .036 & -.047 & -.715 & .475 \\
\hline \multirow[t]{7}{*}{4} & $($ Constant $)$ & 44.447 & 4.285 & & 10.372 & .000 \\
\hline & Religious Affiliation & 2.692 & 2.422 & .060 & 1.111 & .267 \\
\hline & Ethnicity & -.282 & .419 & -.037 & -.673 & .502 \\
\hline & Yrs as Manager & .153 & .100 & .094 & 1.537 & .125 \\
\hline & Tenure Current Job & -.097 & .132 & -.044 & -.730 & .466 \\
\hline & \# Direct Reports & .011 & .031 & .020 & .354 & .724 \\
\hline & CollectivismMean & 6.926 & .701 & .539 & 9.878 & .000 \\
\hline
\end{tabular}

a. Dependent Variable: LMXQuality

Table 3. Multiple regression analysis for Total LMX Quality

\begin{tabular}{|c|c|c|c|c|c|c|c|c|}
\hline \multirow[b]{2}{*}{ Model } & \multirow[b]{2}{*}{$\mathbf{R}$} & \multirow[b]{2}{*}{ R Square } & \multirow{2}{*}{$\begin{array}{l}\text { Std. Error } \\
\text { of the } \\
\text { Estimate }\end{array}$} & \multicolumn{5}{|c|}{ Change Statistics } \\
\hline & & & & $\begin{array}{c}\text { R Square } \\
\text { Change }\end{array}$ & F Change & df1 & df2 & Sig. F Change \\
\hline 1 & $.137^{\mathrm{a}}$ & .019 & 14.29443 & .019 & 4.873 & 1 & 254 & $.028 *$ \\
\hline 2 & $.138^{\mathrm{b}}$ & .019 & 14.32131 & .000 & .048 & 1 & 253 & .827 \\
\hline 3 & $.179^{c}$ & .032 & 14.31021 & .013 & 1.131 & 3 & 250 & .337 \\
\hline 4 & $.552^{\mathrm{d}}$ & .305 & 12.15394 & .272 & 97.576 & 1 & 249 & $.000 *$ \\
\hline
\end{tabular}

*Note. $p<.05$

a. Predictors: (Constant), Religious Affiliation

b. Predictors: (Constant), Religious Affiliation, Ethnicity

c. Predictors: (Constant), Religious Affiliation, Ethnicity, Tenure Current Job, \# Direct Reports, Yrs as Manager

d. Predictors: (Constant), Religious Affiliation, Ethnicity, Tenure Current Job, \# Direct Reports, Yrs as Manager, CollectivismMean

As shown in Table 3, the results of a multiple regression analysis of Total LMX Quality, consisting of participant age, gender, religious affiliation, years of education, and years of work experience in block one, ethnicity in block two, and years as a manager, tenure in the current job, and number of direct reports in block three, and the diversity dimension of collectivism, indicated that there were two significant reduced models. Collectivism and religious affiliation were both predictor variables with regard to participant's ratings of diversity in the organization and their attitudes toward their immediate supervisor and perceptions of leadership. Results of the regression analysis provided in Table 2 indicated that the diversity dimension, collectivism, was the driving factor causing the significant influence $(\beta=.539, p=.00)$. The initial correlation in Table 1 between each of the four dimensions of LMX and the diversity dimension of collectivism used in this study indicated that diversity was a significant predictor of the dependent variable, LMX Quality. Further regression analysis, using the stepwise method, indicated that the diversity dimension, collectivism, was the driving factor of this relationship, thus supporting Hypothesis 2. This result indicates that the more collectivistic the respondents believed the work culture to be, the more positively they rated their immediate supervisor and perceptions of leadership $\left(\left(R^{2}=.31, \mathrm{p}=.00 ; \beta=.539, r_{p}=.531, p=.00\right)\right.$.

Religious affiliation, as a control factor, accounted for $1.9 \%$ of the variance in the relationship $\left(\beta=.139, r_{p}\right.$ $=.138, p=.028)$. Those who indicated religious affiliation rated high on collectivism. They also regarded their relationship with their immediate supervisors more positively, with a higher LMX rating. 
The results of a multiple regression using the same predictor variables and the criterion variable of LMX Contribution again had two significant predictors, collectivism $\left(R^{2}=.102, p=.00 ; \beta=.249, r_{p}=.247, p=.00\right)$, and religious affiliation which accounted for $2.4 \%$ of the variance in the relationship $\left(\left(\beta=-.159, r_{p}=-.158, p=.012\right)\right.$. Results found the diversity dimension, collectivism, to be the driving factor of this relationship, reaffirming Hypothesis 2. Having a religious affiliation and the more collectivistic the organizational culture, the more positively the respondents rated their relationship quality with the leader-member exchange (LMX). Table 4 provides the results for this multiple regression analysis.

Table 4. Multiple regression analysis for LMX Contribution

\begin{tabular}{|c|c|c|c|c|c|c|c|c|}
\hline \multirow[b]{2}{*}{ Model } & \multirow[b]{2}{*}{$\mathbf{R}$} & \multirow[b]{2}{*}{ R Square } & \multirow[b]{2}{*}{$\begin{array}{l}\text { Std. Error of } \\
\text { the Estimate }\end{array}$} & \multicolumn{5}{|c|}{ Change Statistics } \\
\hline & & & & $\begin{array}{c}\text { R Square } \\
\text { Change }\end{array}$ & F Change & df1 & df2 & Sig. F Change \\
\hline 1 & $.155^{\mathrm{a}}$ & .024 & 1.07441 & .024 & 6.283 & 1 & 254 & $.013 *$ \\
\hline 2 & $.156^{\mathrm{b}}$ & .024 & 1.07647 & .000 & .028 & 1 & 253 & .867 \\
\hline 3 & $.208^{\mathrm{c}}$ & .043 & 1.07224 & .019 & 1.666 & 3 & 250 & .175 \\
\hline 4 & $.319^{\mathrm{d}}$ & .102 & 1.04123 & .058 & 16.112 & 1 & 249 & $.000 *$ \\
\hline
\end{tabular}

*Note. $p<.05$

a. Predictors: (Constant), Religious Affiliation

b. Predictors: (Constant), Religious Affiliation, Ethnicity

c. Predictors: (Constant), Religious Affiliation, Ethnicity, Tenure Current Job, \# Direct Reports, Yrs as Manager

d. Predictors: (Constant), Religious Affiliation, Ethnicity, Tenure Current Job, \# Direct Reports, Yrs as Manager, CollectivismMean

The results of a multiple regression using the same predictor variables and the criterion variable of LMX Professional Respect revealed four significant predictors; collectivism, religious affiliation, age, and years as a manager. Results showed that the more collectivistic the respondents believed the work culture to be, the more positively they rated their immediate supervisor and perceptions of leadership $\left(R^{2}=.278, p=.00 ; \beta=.477, r_{p}=\right.$ $.464, p=.00)$. Religious affiliation accounted for $2.9 \%$ of the variance in the relationship $\left(\left(\beta=.169, r_{p}=.169, p=\right.\right.$ $.007)$, age accounted for $4 \%$ of the variance $\left(\beta=-.138, r_{p}=.139, p=.026\right.$, while years as a manager accounted for $8 \%$ of the variance in the relationship $\left(\beta=.212, r_{p}=.142, p=.025\right)$. Thus, the more collective the organizational culture, the more years as a manager, the younger the individuals, and having a religious affiliation, the more positively participants rated their leader-member exchange model. Results of the multiple regression analysis are provided in Table 5.

Table 5. Multiple regression analysis for LMX Professional Respect

\begin{tabular}{|c|c|c|c|c|c|c|c|c|}
\hline \multirow[b]{2}{*}{ Model } & \multirow[b]{2}{*}{$\mathbf{R}$} & \multirow[b]{2}{*}{ R Square } & \multirow{2}{*}{$\begin{array}{l}\text { Std. Error of } \\
\text { the Estimate }\end{array}$} & \multicolumn{5}{|c|}{ Change Statistics } \\
\hline & & & & $\begin{array}{l}\text { R Square } \\
\text { Change }\end{array}$ & F Change & df1 & df 2 & Sig. F Change \\
\hline 1 & $.169^{\mathrm{a}}$ & .029 & 1.53784 & .029 & 7.497 & 1 & 254 & $.007 *$ \\
\hline 2 & $.218^{\mathrm{b}}$ & .047 & 1.52590 & .019 & 4.991 & 1 & 253 & $.026 *$ \\
\hline 3 & $.222^{\mathrm{c}}$ & .049 & 1.52749 & .002 & .475 & 1 & 252 & .491 \\
\hline 4 & $.283^{\mathrm{d}}$ & .080 & 1.51144 & .031 & 2.793 & 3 & 249 & $.041 *$ \\
\hline 5 & $.528^{\mathrm{e}}$ & .278 & 1.34153 & .198 & 68.070 & 1 & 248 & $.000 *$ \\
\hline
\end{tabular}

*Note. $p<.05$

b. Predictors: (Constant), Religious Affiliation, Age

c. Predictors: (Constant), Religious Affiliation, Age, Ethnicity

d. Predictors: (Constant), Religious Affiliation, Age, Ethnicity, \# Direct Reports, Tenure Current Job, Yrs as Manager

e. Predictors: (Constant), Religious Affiliation, Age, Ethnicity, \# Direct Reports, Tenure Current Job, Yrs as Manager, CollectivismMean

\section{Leadership}

This study asked participants to rate the degree to which the four dimensions of the Leader-Member Exchange (LMX) Model were instrumental in measuring their attitudes toward their supervisor and perceptions of leadership. The results of the initial multiple regression analysis in Table 1 indicated that the independent variable, labeled collectivism, was found to be positively correlated with the dependent variable, labeled LMXQuality $(r=$ $.54, p<.01)$. Further regression analysis revealed that the diversity dimension, collectivism, was the driving factor of this relationship $(\beta=.539, p=.00)$. This indicates that the more collectivistic the participants believed the work 
culture to be, the higher they rated their immediate supervisor and perceptions of leadership. Results of this regression analysis are provided in Table 2

Additional regression analysis was run for each of the four LMX dimensions of Contribution, Loyalty, Affect, and Professional Respect. All four of the LMX dimensions were found to have a significant relationship with the diversity dimension, collectivism. Further analysis indicated that only the two LMX dimensions of Contribution and Professional Respect were found to have a significant relationship with both, the diversity dimension of collectivism and religious affiliation. (Results of these analyses are provided in Tables 4 and 5).

\section{DISCUSSION}

The results of this study presented findings that were both intriguing and beneficial to current research. Research shows that collectivist cultures tend to have a high degree of interdependency among group members in the organization. This interdependency conceivably promotes a higher value on diversity. Aycan, Kanungo, Mendonca, Yu, Deller, Stahl, and Kurshid (2000) found that managers who prefer collectivism as a cultural value, also ascertain that employees in their organizations will exhibit a high degree of obligation toward other organizational members. Herrera, Duncan, Green, Ree, and Skaggs (2011) found that organizations with a strong collectivist culture was a strong predictor of how positively participants rated their organizations support for diversity, recruitment efforts, diversity training for mentors, and employees with disabilities. Brandt (1974) and Choi (1996) found that members of collectivist cultures are more likely to engage in group activities than members of individualistic cultures. And Wheeler, Reis and Bond (1989) found that relationships in collectivist cultures tend to be longer in duration, more intimate, and more group-oriented than relationships in individualistic cultures.

It is unclear from this study whether participants who prefer a collectivist culture tended to self-select toward organizations that promote diversity or whether organizations that promote diversity tend to acculturate workers toward a preference for collectivism. Erez and Earley (1993) found that human resources practices differed between organizations that promoted individualistic cultures to those that promoted collectivistic cultures. Those organizations promoting collectivist cultures emphasized interdependence and obligation to others. Erez and Earley assume that these organizational cultural values likely manifest themselves during employee recruitment, performance appraisal, and job design.

The increased growth of women, minorities, and other cultures in the workplace has necessitated the need for empirical research to provide insight into the relationship between diversity and the LMX model dimensions. The results of this study indicate that promoting a more collectivist rather than individualistic or gender-based culture is associated with the increased rating of multiple aspects of leadership effectiveness. If a company's desire is to have increased ratings of leadership effectiveness, then the organization should begin to incorporate those practices necessary to achieve desired objectives. This includes creating a culture in which the individual is viewed as interdependent with groups, in which people emphasize relatedness with groups, or in which individuals have fewer social interactions, but interactions tend to be longer and more intimate (House et al., 2004).

An organizational culture that is collectivist in nature also includes an emphasis in HRM practices, including selection, performance appraisal, and termination processes. With respect to selection in collectivist cultures, this is commonly influenced by the relation that applicants have with members within the organization. The most qualified person could very well be the one with the best contacts and relationships with the organization. With regard to performance appraisals, workers in collectivist cultures prefer less formal appraisal practices and are less likely to prefer rewards based on individual merit. And with respect to terminations, poor performance is more frequently tolerated and the quality of the relationship with the organization has more of an impact on whether one is terminated.

\section{CONCLUSION AND LIMITATIONS}

This study makes several significant contributions to the literature on leadership, particularly with respect to how collectivism and religious affiliation impacts the Multidimensional Measure of Leader-Member Exchange (LMX-MDM). Although the LMX model has emerged as one of the most enduring theories for characterizing 
leadership behavior, little was known about how collectivism and religious affiliation can impact the LMX model for increased leadership effectiveness. This paper also alerts organizations as to the HRM policies and practices that may need to be applied to arrive at desired results. Results of this current study indicate that the diversity dimension of collectivism and religious affiliation does indeed have a significant impact on the LMX model, particularly with regard to the LMX dimensions of Contribution and Professional Respect. In addition, collectivism was found to be the driving factor of influence on the LMX model for increased leadership effectiveness. Organizations should recognize that HRM policies and practices will only lead to positive results when applied in the proper context. In other words, organizations should know which policies are most appropriate when dealing with a collectivist culture and when they are no longer applicable. These findings stress the importance of implementing the right corporate strategy based on the organization's culture. With the increase in globalization, organizations should be prepared to re-evaluate their policies and know when to adapt to changes in organizational culture. Only then will they be able to take full advantage of organizational diversity practices to increase leadership effectiveness to its fullest capacity.

This study was confronted with the usual limitations associated with the use of the survey method. For example, limited in its ability to account for unforeseen variables, surveys can only find associations rather than casual relationships between independent variables and dependent variables (McKenna, Hasson, \& Keeney, 2006). Future studies can overcome this problem by combining other methods such as longitudinal studies with surveys, which are administered a number of times over the period of the research. Although subject to limitations, the survey sample size of 300 participants used in this study, nevertheless, displays results that provide significant theoretical and practical contributions to diversity and its effect on the Leader-Member Exchange Model.

Data for this study were collected at both a private and public Texas University. To be able to generalize this study's results to a larger number of organizations, future research would profit from including a more varied sample of universities and workplaces.

In addition, survey questionnaires were only distributed to nontraditional students in graduate and undergraduate programs. Respondents of the study were students who were also employed in a wide array of organizations while attending school. Future studies could enhance the generalizability of the results by collecting data from traditional full-time students and students who are enrolled in other types of programs.

In summary, the current study results show there is a significant relationship between the diversity dimension, collectivism, and religious affiliation and its effect on the Leader-Member Exchange Model, which can lead to increased leadership effectiveness. Results further show that collectivism is the driving factor influencing this significant relationship. These findings, without a doubt, have important implications for organizations that remain challenged in implementing the proper HRM policies and the right corporate strategy based on the organization's culture.

\section{AUTHORS' INFORMATION}

Phyllis A. Duncan is an Associate Professor in the School of Business and Leadership at Our Lady of the Lake University where she teaches and is coordinator of the Leadership Studies Doctoral Program. She has held various leadership positions in businesses including CEO, COO, and Senior Vice President. Phyllis hold a Bachelor's of Science from University of the Ozarks, a Masters of Business Administration from University of Arkansas, a Masters of Science in Industrial Engineering from Southwest University, and a Doctorate of Philosophy from University of the Incarnate Word. She can be reached at paduncan@lake.ollusa.edu.

Richard Herrera is currently an Assistant Professor of Management at Texas A\&M University- Texarkana. His primary teaching areas include operations management, human resources, organizational behavior, labor relations and leadership in organizations. He holds a Bachelors of Business and a Masters of Business Administration from St. Mary's University, and received his Ph.D. in Leadership Studies from Our Lady of the Lake University. His research interests are in the areas of Organizational Diversity Practices, Diversity Management, and Organizational Culture \& Behavior. He has served on numerous corporate boards and has dealt extensively in the areas of Diversity and Diversity Management in organizations (richard.herrera@tamut.edu). 


\section{REFERENCES}

Agocs, C., \& Burr, C. (1996). Employment equity, affirmative action and managing diversity: Assessing the differences. International Journal of Manpower, 17(4-5), 30-45.

Avery, D. R. (2003). Reactions to diversity recruiting advertising: Are differences black and white? Journal of Applied Psychology, 88(4), 672-679.

Aycan, Z., Kanungo, R., Mendonca, M., Yu, K., Deller, J., Stahl, G., \& Kurshid, A. (2000). Impact of culture on human resource management practices: A 10 country comparison. Applied Psychology: An International Review, 49(1), 192-221.

Barak, I. (1999). Applying the Need for Closure Framework to Information Processing in Cross-Cultural Business Situations, Dissertation Abstracts International, 59, 7b, 37-43.

Bell, S.T., Villado, A. J., Lukasik, M. A., Belau, L., \& Brigg, A. L. (2011). Getting specific about demographic diversity variable and team performance relationships: a meta-analysis. Journal of Management, 37(3), 709-743.

Brandt, V. (1974). Skiing cross-culturally. Current Anthropology, 15, 64-66.

Carr-Ruffino, N. (1992). Diversity in the workplace. New York: The Guildford Press.

Charles, J. (2003). Diversity management: An exploratory assessment of minority group representation in state government. Public Personnel Management, 32(4), 561-577.

Choi, Y. (1996). The self in different context: Behavioral analysis. Paper presented at the International Congress of Psychology.

Cox, T. H., and Blake, S. (1991). Managing cultural diversity: Implications for organizational competitiveness. Academy of Management Executive, 5(3), 45-56.

Dienesch R. M., \& Liden, R. C. (1986). Leader-member exchange model of leadership: A critique and further development. Academy of Management Journal, 11(3), 818-634.

Erez, M., \& Earley, P. (1993). Culture Self-Identity and Work, New York: Oxford University Press.

Friedlander, F. (1975). Emerging and contemporary lifestyles: An inter-generational issue. Human Relations, 28(4), 329-347.

Furnham, A. (1997). The half full or half empty glass: The Views of the economic optimist vs. pessimist. Human Relations, 50(2), 197-209.

Giacalone, R.A. and C.L. Jurkiewicz, (2003). Toward a Science of Workplace Spirituality, in R.A. Giacalone and C.L. Jurkiewicz (eds.), Handbook of Workplace Spirituality and Organizational Performance (M.E. Sharpe, Armonk), p. 3-28)

Gilbert, J. A., \& Stead, B. A. (1999). Stigmatization Revisited: Does diversity management make a difference in applicant success? Group and Organization Management, 24(2), 239-256.

Gonzalez, J. A., \& DeNisi, A. S. (2009). Cross-level effects of demography and diversity climate on organizational attachment and firm effectiveness. Journal of Organizational Behavior, 30, 21-40.

Graen, G. (1976). Role-making processes within complex organization. In M.D. Dunnette (Ed.), Handbook of Industrial and Organizational Psychology (p. 1201-1245). Chicago: Rand McNally.

Graen, G. B., \& Scandura, T. A. (1987). Toward a psychology of dyadic organizing. Research in Organizational Behavior, 9, 175-208.

Graen, G. B., \& Uhl-Bien, M. (1995). Development of leader-member exchange (LMX) theory of leadership over 25 years: Applying a multi-level domain perspective. Leadership Quarterly, 6, 219-247.

Harrison, D.A., Price, K.H., and Bell, M.P. (1998), Beyond Relational Demography: Time and the Effects of Surface and Deep Level Diversity on Work Group Cohesion, Academy of Management Journal, 41, p 96107.

Herrera, R., Duncan, P. A., Green, M., \& Skaggs, S.L. (2012). The effect of gender on leadership. Global Business and Organizational Excellence, 31(2), 37-48.

Herrera, R., Duncan, P. A., Green, M., Ree, M., \& Skaggs, S. L. (2011). Organizational culture as a predictor of organizational diversity practices. The Business Journal of Hispanic Research, 5(1), 73-85.

Herrera, R., Duncan, P. A., Green, M., Ree, M., \& Skaggs, S. L. (2011). The relationship between attitudes toward diversity management in the southwest USA and the GLOBE study cultural preferences. The International Journal of Human Resource Management, 22(12), 2629-2646.

Homan, A. C., Hollenbeck, J. R., Humphrey, S. E., van Knippenberg, D., Ilgen, D. R., \& Van Kleef, G.A. (2008). Facing differences with an open mind: Openness to experience, salience of intragroup differences, and 
performance of diverse work groups. Academy of Management Journal, 51, 1204-1222.

House, R., Hanges, P., Javidan, M., Dorfman, P., \& Gupta, V. (2004). Culture, leadership, and organizations: The GLOBE Study of 62 societies. London: Sage Publications.

Jacobs, T.O. (1971). Leadership and exchange in formal organizations. Alexandria, VA: HumRRO.

Johnston, W., \& Packer, A. (1987). Workforce 2000: Work and workers for the $21^{\text {st }}$ century, Indianapolis, IN: Hudson Institute.

Judy, R., \& D'Amico, C. (1997).Workforce 2020: Work and workers in the $21^{\text {st }}$ century, Indianapolis, IN: Hudson Institute.

Katz, D., \& Kahn, R. L. (1978). The social psychology of organizations. ( $2^{\text {nd }}$ ed.). New York: Wiley.

Liden, R. C., \& Maslyn, J. M. (1998). Multidimensionality of leader-member exchange: An empirical assessment through scale development. Journal of Management, 24(1), 43-72.

Liden, R. C., Sparrowe, R. T., \& Wayne, S. J. (1997). Leader-member exchange theory: The past and potential for the future. In Ferris, G. R. (Ed.), Research in Personnel and Human Resources Management, 15, p. 47119). Greenwich, CT: Elsevier Science/JAI Press.

McKenna, H., Hasson, F., \& Keeney, S. (2006). "Surveys", in The Research Process in Nursing (5 ${ }^{\text {th }}$ ed), eds. K. Gerrish \& A. Lacey, Oxford: Blackwell, pp. 260-273.

Meister, J., \& Willyerd, K. (2010). The 2020 workplace: How innovative companies attract, develop, and keep tomorrow's employees today. New York: HarperCollins.

Meyers, V., \& Dreachslin, J. (2007). Recruitment and retention of a diverse workforce: Challenges and opportunities. Journal of Healthcare Management, 52(5), 290-298.

Nahrgang, J. D., Morgeson, F. P., \& IIies (2009).The Development of leader-member exchanges: Exploring how personality and performance influence leader and member relationships over time. Organizational Behavior and Human Decision Processes, 108, 256-266.

Ng, E.S., and Tung, R.L. (1998), Ethno-Cultural Diversity and Organizational Effectiveness: A Field Study, The International Journal of Human Resource Management, 9(6), 980-995.

Nielsen, E., \& Edwards, J. (1982). Perceived feminine role orientation and self-concept. Human Relations, 35(7), 547-558.

Proffitt, W.T., \& Spicer, A. (2006). Shaping the shareholder activism agenda: Institutional investors and global social issues. Strategic Organization, 42(2), 165-190.

Robinson, G., \& Dechant, K. (1997). Building a business case for diversity. Academy of Management Executive, 11(3), 21-31.

Sagie, A., \& Elizur, D. (1996). The structure of personal values: A conical representation of multiple life ideas. Journal of Organizational Behavior, 17(S1), 573-586.

Schriesheim, C. A., Castro, S. L., \& Cogliser, C. C. (1999). Leader-member exchange (LMX) research: A comprehensive review of theory, measurement, and data-analytic practices. Leadership Quarterly, 10, 63113.

Shen, J., D'Netto, B. D., \& Tang, J. (2010). Effects of human resource diversity management on organizational citizen behavior in the chinese context. The International Journal of Human Resource Management, 21(12), 2156-2172.

Shore, L. M., Chung, B., Dean, M. A., Ehrhart, K. H., Jung, D., Randel, A., \& Singh, G. (2009). Diversity and inclusiveness: Where are we now and where are we going? Human

Resource Management Review, 19, 117-133.

Somers, M. J., Finch, L., \& Birnbaum, D. (2010). Marketing nursing as a profession: Integrated marketing strategies to address the nursing shortage. Health Marketing Quarterly, 27, 291-306.

Tracey, P. (2012). Religion and Organization: A Critical Review of Current Trends and Future Directions. The Academy of Management Annals, 6, 87-134.

Triandis, H.C. (1990). Cross-Cultural Studies of Individualism and Collectivism, in Nebraska Symposium on Motivation: Cross-Cultural Perspective, Current Theory and Research in Motivation, ed. J.J. Berman, Lincoln, NS: University of Nebraska Press, pp. 41-133

Wheeler, L., Reis, H. T., \& Bond, M. (1989). Collectivism-individualism in everyday social life: The middle kingdom and the melting pot. Journal of Personality and Social Psychology, 57, 79-86.

Williams, M. L, \& Bauer. T. N. (1994). The effect of a managing diversity policy on organizational attractiveness. Group and Organization Management, 19(3), 295-308. 